\title{
Simultaneous double discrimination response following brain bisection'
}

\author{
M. S. GAZZANIGA AND R. W. SPERRY
}

DIVISION OF BIOLOGY, CALIFORNIA INSTITUTE OF TECHNOLOGY PASADENA, CALIFORNIA

The performance of two choice reactions, one with each hand, in response to two visual discrimination tasks presented simultaneously, one in each half of the visual field, normally takes much longer than the performance of either one alone. In commissurotomized human patients, however, the double task was performed as rapidly as the single task. The results conform with the view that the neocortic al commissures serve to unify adjustment to the visual world (Gazzaniga ct al, 1965) and their presence tends to prevent the two half brains from making discordant volitional decisions.

When the cerebral hemispheres have been separated by complete surgical section of the neocortical commissures, each of the two disconnected hemispheres continues to function much as before except that their activities lack the high interdependence and unity that normally prevails. It has become clear from a number of studies in man (Gazzaniga et al, 1962,1963, 1965), as well as in animals (Sperry, 1961, 1964), that the two separated hemispheres continue to cooperate much of the time in performing a single unified function. Each of the two disconnected hemispheres is also able to take over the directive controls of total behavior on different occasions. Left and right hemispheres may alternate in dominating the control of the lower motor system. When one hemisphere is in command, conflicting or interfering activity in the other hemisphere tends, as a rule, to be excluded from the motor system which swings over entirely to mediating the higher functions of whichever hemisphere is dominant at the moment. An exception occurs at times in the control of the hands, especially in man, where dissociated and even antagonistic performances can be carried out simultaneously under certain conditions.

It has been shown experimentally in monkeys that the two separated hemispheres working in parallel are able to perceive, learn, and remember contradictory discrimination tasks under conditions involving a polarized light technique whereby the separate hemispheres are made to see different things in the same place at the same time (Trevarthen, 1962). Rapid alternation of hemispheric dominance within the time span of a response trial in the foregoing could not be excluded. Also there were indications of the presence of unifying factors that tended to favor the use of one hemisphere at a time in a majority of cases.

Beyond the foregoing there is little information available concerning the extent to which the disconnected hemispheres can carry out simultaneously activities that normally would produce mutual interference in the presence of the commissures. The following is the result of an attempt to investigate this question further in commissurotomized human subjects. A visual discrimination task was flashed to the left hemisphere first and then together with another different discrimination task to the right hemisphere and the reaction times to the single and double presentation were measured and compared with normal and with preoperative readings. The obvious interference produced by pairing the tasks under control conditions stood in marked contrast to the lack of interference that was found to prevail in the absence of the commissures.

\section{Procedure}

Four normal and four operated Ss were tested. The operated Ss were all patients of Drs. Philip Vogel and Joseph Bogen of the California College of Medicine and had undergone midline section of the neocortical commissures at the White Memorial Hospital in an effort to control advanced epileptic seizures (Bogen \& Vogel, $1962,1965)$. Results of other functional studies carried out on these same cases have been reported elsewhere (Gazzaniga et al, 1962, 1963, 1965). All operated Ss, both before and after surgery, were receiving several anticonvulsant drugs in varying amounts, which uniformly slowed down their reaction time both pre- and postoperatively.

Each $S$ was seated in front of the panel pictures in Fig. 1, with gaze fixed on a central point and was instructed to respond as fast as possible to one of a pair of stimuli presented in either or both visual fields. In all $\mathrm{Ss}$ the left hemisphere-right hand combination was required to respond to the green of a red-green discrimination pair presented in the right visual field, and the left hand-right hemisphere combination to a light-dark discrimination task in the left field. Each trial was preceded by instructions to the $S$ to look at a central point on the panel. When accurate fixation was attained, as checked by the experimenter behind the screen, the stimuli were tachistoscopically presented (tungsten 24 V DC source energized for $0.15 \mathrm{sec}$.). Presentation of visual material in this manner insured that stimuli in the right visual field would be projected solely to the

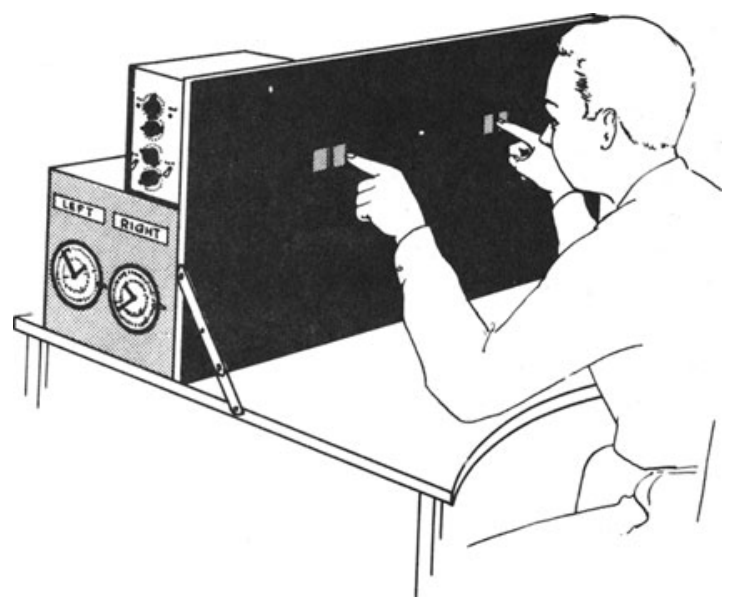

Fig. 1. Testing apparatus: While subject fixated central point, stimuli were flashed onto the translucent response panels. 
Table 1. Reaction Times to Visual Stimuli in Milliseconds*

\begin{tabular}{|c|c|c|c|c|c|c|c|c|c|c|}
\hline \multirow[t]{2}{*}{$\begin{array}{l}\text { Subject } \\
\text { (normal and pre-op.) }\end{array}$} & \multicolumn{2}{|c|}{$\begin{array}{c}\text { R. Hand } \\
\text { (Trials 1-10) }\end{array}$} & \multicolumn{4}{|c|}{$\begin{array}{l}\text { R. Hand-L. Hand } \\
\text { (Trials } 11-20 \text { ) }\end{array}$} & \multicolumn{2}{|c|}{$\begin{array}{c}\text { R. Hand } \\
\text { Trials 21-30) }\end{array}$} & \multirow[b]{2}{*}{$p\left(M_{2}-M_{1}\right)$} & \multirow[b]{2}{*}{$p\left(M_{2}-M_{4}\right)$} \\
\hline & $M_{1}$ & S.D. & $M_{2}$ & S.D. & $\mathrm{M}_{3}$ & S.D. & $M_{4}$ & S.D. & & \\
\hline $\begin{array}{l}\text { GRN } \\
\text { TRB } \\
\text { HML } \\
\text { SRP } \\
\text { Case III (A.A.) } \\
\text { Case IV (L.B.) }\end{array}$ & $\begin{array}{l}438 \\
465 \\
380 \\
439 \\
704 \\
727 \\
\end{array}$ & $\begin{array}{r}57 \\
120 \\
55 \\
228 \\
176 \\
158 \\
\end{array}$ & $\begin{array}{r}695 \\
770 \\
470 \\
574 \\
1272 \\
1667 \\
\end{array}$ & $\begin{array}{r}97 \\
140 \\
88 \\
70 \\
213 \\
750 \\
\end{array}$ & $\begin{array}{r}694 \\
300 \\
464 \\
678 \\
1110 \\
1227 \\
\end{array}$ & $\begin{array}{r}96 \\
120 \\
95 \\
83 \\
254 \\
580 \\
\end{array}$ & $\begin{array}{l}391 \\
496 \\
374 \\
376 \\
629 \\
682 \\
\end{array}$ & $\begin{array}{r}56 \\
83 \\
73 \\
64 \\
117 \\
149 \\
\end{array}$ & $\begin{array}{l}<.005 \\
<.005 \\
<.05 \\
<.005 \\
<.005 \\
<.005 \\
\end{array}$ & $\begin{array}{l}<.005 \\
<.005 \\
<.025 \\
<.005 \\
<.005 \\
<.005\end{array}$ \\
\hline \multicolumn{11}{|l|}{ (operated) } \\
\hline $\begin{array}{l}\text { Case I (W.J.) } \\
\text { Case II (N.G.) } \\
\text { Case III (A.A.) } \\
\text { Cose IV (L.B.) }\end{array}$ & $\begin{array}{r}1150 \\
766 \\
705 \\
700\end{array}$ & $\begin{array}{l}138 \\
156 \\
175 \\
152\end{array}$ & $\begin{array}{l}869 \\
777 \\
724 \\
594\end{array}$ & $\begin{array}{r}92 \\
153 \\
170 \\
92\end{array}$ & $\begin{array}{l}798 \\
869 \\
741 \\
566\end{array}$ & $\begin{array}{l}104 \\
224 \\
199 \\
114\end{array}$ & $\begin{array}{l}848 \\
706 \\
582 \\
600\end{array}$ & $\begin{array}{l}110 \\
280 \\
237 \\
161\end{array}$ & $\begin{array}{l}\text { N.S. } \\
\text { N.S. } \\
\text { N.S. } \\
\text { N.S. }\end{array}$ & $\begin{array}{l}\text { N.S. } \\
\text { N.S. } \\
\text { N.S. } \\
\text { N.S. }\end{array}$ \\
\hline
\end{tabular}

* $R$. Hand responds to red'green discrimination in right half visual field. $L$. Hand responds to bright/dark discrimination in left half visual field. Probability calculated from paired observations by one tailed t test. N.S. .05

left hemisphere and stimuli in the left visual field to the right hemisphere. The pair of stimuli for each visual field was presented side by side on two translucent screens $3.5 \mathrm{~cm} \times 4.5 \mathrm{~cm}$ by means of a one plant projector unit. The right-left positioning of each pair was interchanged on a pseudorandom schedule. The response time was measured from the beginning of the electronic-flash until the timing circuit was opened by the S's pressing of the correct response panel.

The Ss positioned the index finger of each hand upon the $1 / 4$ in. vertical partition between the two response panels of each pair of screens. Following stimulus presentation the finger thus positioned was moved quickly to left or right on whichever side the chosen stimulus appeared. The entire test sequence took approximately $30 \mathrm{~min}$. The trials were run with the right hand working the red-green discrimination presented in the right visual field. This was followed by 10 trials in which both hands were used in parallel, the left hand responding to the black-white discrimination simultaneously presented in the left visual field with the color stimuli in the right field. Subsequently, the right hand worked alone for ten trials of the red-green discrimination presented in the right visual field.

\section{Results and Discussion}

The results are summarized in Table1.t values were calculated from correlated observations because most Ss showed practice effects with the right hand within each series of scores. The normal Ss on the average took 40 percent longer to perform the double discrimination task than when the one task was performed alone. The operated Ss, by contrast, were able to perform the double discrimination-response task as rapidly as they did the single task alone. Preoperative scores were available for Cases III and IV. The reaction times in both of these were slower preoperatively than in the normals, presumably due largely to the anticonvulsant medication. These reaction times in these cases were not significantly increased after surgery.

Absence of the normal increase in reaction time in the operated Ss when they were required to perform two discrimination responses simultaneously, one through each hemisphere, would seem to indicate a lack of interference through the commissures that was present in the normal subjects. Presumably this reflects a unifying role of the commissures that under normal conditions would act to keep the two hemispheres working in harmony on the same task.

The ability of each hemisphere to carry out separately in parallel a visual discrimination and to respond to it voluntarily with the corresponding hand in no more time than if each were working alone provides further evidence for the view that cerebral commissurotomy creates two separate mental entities each capable of operating in the presence of dissociated function in the other.

\section{References}

Bogen, J. E., \& Vogel, P. J. Cerebral Commissurotomy: A Case Report. Bull. Los Angeles Neurol. Soc., 1962, 27, 169.

Bogen, J. E., Fisher, E. D., \& Vogel, P. J. Cerebral Commissurotomy: A Second Case Report. J. A. M. A., 1965, 194, 1328-1329.

Gazzaniga, M. S., Bogen, J. E., \& Sperry, R. W. Some functional effects of sectioning the cerebral commissures in man. Proc. Nat. Acad. Sci., 1962, 48, 1765-1769.

Gazzaniga, M. S., Bogen, J. E., \& Sperry, R. W. Laterality effects in somesthesis following cerebral commissurotomy in man. Neuropsychologia, 1963, 1, 209-215.

Gazzaniga, M. S., Bogen, J. E., \& Sperry, R. W. Observation on visual perception after disconnection of the cerebral hemispheres in man. Brain, 1965, 58, 221-236.

Sperry, R. W. Cerebral organization and behavior. Science, 1961 , $133,1749-1757$.

Sperry, R. W. The great cerebral commissure. Scient. American, $1964,210,42-52$.

Trevarthen, C. B. Double visual learning in split-brain monkeys. Science, 1962, 136, 258.

\section{Note}

1. Aided by USPHS Grant MH 3372 and the Frank P. Hixon Fund of the California Institute of Technology. 